anatomical and histological evidence summarised in my recent paper-will now see that unless they can disprove the statements of Prof. Marshall, Dr. Jickeli, Dr. P. Herbert Carpenter, and myself, they are bound to admit my doctrine, and to show how their theoretical homology is to be reconciled with it,

William B. Carpenter

56, Regent's Park Road, London, N.W., November 3

\section{Natural Science for Schools}

THE thoughtful and suggestive paper of Prof. Armstrong in the last number of NATURE (p. 19) is to be commended to the attention both of science teachers and of the head masters of our schools. It is undoubtedly true that, with few exceptions, science is still either completely neglected by our schools or handled in a way which docs not at all tend to advance its interests. When it is made a " refuge for the destitute," or considered only fit for those intellectually unequal to the study of classics and mathematics, no wonder that observant head masters conclude that little good is to be got from it.

As a science master of many years' experience (having been in fact responsible for the introduction of science into two of the schools named by Prof. Armstrong as exceptions to the universal indifference), you will perhaps allow me to call attention to the importance of Prof. Armstrong's paper, and to give the conclusions to which my own experience has led me.

The importance of clearly understanding the purpose with which science is to be studied, and the distinction to be borne in mind between the best curriculum for those who are to be professed chemists and those who will not carry the study of chemistry beyond their school-days is obvious; but I wish to point out how entirely science masters are at the mercy of examiners, both of University examiners, periodically examining a school, and of examiners for open scholarships. My own experience is to the point. Fully persuaded of the uselessness of attempting to make an analytical machine out of the ordinary school-boy giving two or three hours a week to chemistry for two or three years, and of the very small amount of education to be obtained from such a course, I endeavoured to model my instruction in practical chemistry much upon the lines adopted by Prof. Armstrong, and exemplified in the appendix to his paper. When the examinations came, it was duly explained to the examiner that the course of instruction adopted had been unusual, but, all the same, the papers set were of the usual kind:- "Analyse the mixture A," "Determine the metals and acids present in the solution B," \&c. On such a paper, of course, the boys failed, and a depreciatory report was sent up by the examiners, with the result that the governors of the school thought it their duty to interfere, and request that " more attention should be given to practical chemistry." Consequently my attempt had to be abandoned, and we returned to our " testtubing."

Scholarship examinations, being presumably of those who will carry the study much further, may more reasonably demand a knowledge of the ordinary methods of analysis, but I am glad to see that a considerable change has taken place in the papers set, and that now the questions proposed are often such as to place the mechanical analyst at a disadvantage, and to encourage the intelligent observation and interpretation of phenomena.

Prof. Armstrong of course writes as a chemist. But there can be no doubt that certain portions of physics are educationally more useful, and it seems to be only the difficulty of arranging practical work in physics which has led to the present state of things, where practical science work in schools means nearly always practical chemistry. But Prof. Armstrong's protest against allowing this to degenerate into "test-tubing" should not be disregarded. There seems also no reason why elementary instruction in science-whether chemistry, or botany, or physiography-should not deal first with the familiar things of everyday life. I think much more training is to be got by determining, as Prof. Armstrong suggests, the composition of air, the relative combining weights of silver and lead, \&c., than by seeing made any number of oxides of nitrogen, and listening to a description of their properties. There is, however, considerable difficulty in arranging easy methods of determining chemical equivalents which, in inexperienced hands, shall give results not too wide of the mark.

If a boy gets out the atomic weight of oxygen as 9 when the book says it is 16 , or finds the latent heat of steam to be 300 and something when it ought to be 536 , he begins to disbelieve in the precision of the statements made, and it is unfortunately impossible for a beginner to make accurate determinations of combining weights. Less erratic results can, in fact, be obtained in certain selected physical measurements.

The "bareness" of printed instructions is, as Prof. Armstrong remarks, a distinct advantage to the good student, by compelling him to think for himself, but it is fatal to the unintelligent student, to whom "thinking" is the very hardest work he is called upon to do. SCIENCE MASTER

\section{The Recent Lunar Eclipse}

My object in writing is to confirm in some degree the peculiar appearance of the disk, noticed in your last number (vol. $\mathrm{xxx}$ p. 632). The eclipse was seen here under the most favourable circumstances : the obscuration was so grcat that the disk could barely be discerned with the naked eye, and the copper colour usually seen was not noticed. Having watched the moon well into the umbra, my attention was diverted for a while, but, on looking again, at 9.35 G.M.T., I was surprised to see a portion of the north-cast quadrant pretty strongly illuminated ; my attention was again diverted, but on looking a second time at I0. 35 G.M.T., I observed a portion of the south east quadrant
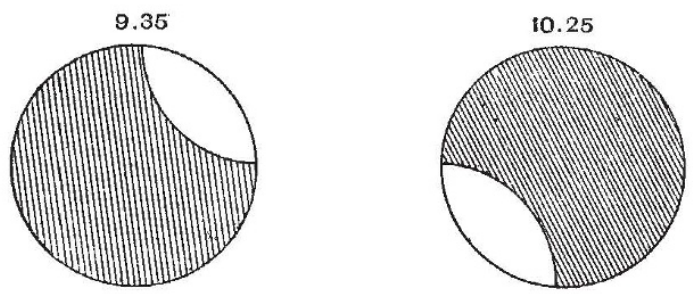

illuminated in a somewhat similar manner. At both times the moon was well within the geometrical umbra. But the remarkable feature was that on both occasions the boundaries of the illuminated portions were, approximately, circular, and convex toward the axis of the umbra, indicating that the refracted solar rays producing these illuminations had crossed the axis of the shadow-cone previous to impinging on the lunar disk. The portions of the refracting annulus of the earth's atmosphere concerned in producing these effects were those superincumbent on the Southern Indian Ocean and the North Atlantic.

WENTWORTH ERCK

\section{Shankill, Co. Dublin, November 4}

\section{The Sky-Glows}

IN using the word "corona" to designate the coloured glare which has accompanied the sun during the past year, I had no intention of employing it in its astronomical sense, but in its ordinary meteorological meaning-which "G. M. H." (NATURE, vol. xxx. p. 633) has overlooked-as referring to the coloured circles on cloud and haze frequently to be seen round the sun and moon, and classed by some observers with halos. By calling the circle now visible round the sun a "corona," I mean that in appearance and probable optical cause it is more like a meteorological corona than like a halo.

May I be allowed to point out a misprint in the first paragraph of my last letter (vol. xxx. p. 633), where it should read "unusual sky phenomena "-the world unversal having been printed for unusual.

Sunderland, November 8

T. W. BACKHOUSE

AFTER sunset this evening there was a peculiar pink flush in the western sky here similar to that which attracted so much attention in England last year. Twenty-five minutes after the sun had gone down, the colour was so vivid as to be reflected from the snows of Mount Baker (10,700 feet), which is about seventy-five miles east of this place. Shortly afterwards it disappeared, but reappeared thirty-five minutes later, prolonging the twilight and making the stars look green, finally dying away very gradually. The weather for the past twelve days has been very wet, and to-night's is the first clear sunset in that time. 